\title{
The Mathematical Culture in Huayao Dai People's Costumes of Xinping*
}

\author{
Ping Wen \\ School of Mathematics and Information Technology \\ Yuxi Normal University \\ Yuxi, China 653100
}

\author{
Danting Sun \\ School of Art and Design \\ Wuhan University of Technology \\ Wuhan, China 430070 \\ Fine Art Academy \\ Yuxi Normal University \\ Yuxi, China 653100
}

\begin{abstract}
The Dai people is one of the ethnic minorities with deep national culture. This article uses the field investigation method to study the Huayao Dai people in the County of Xinping County in Yunnan Province and explores the mathematical culture contained in Huayao Dai people's costumes from the mathematical point of view.
\end{abstract}

Keywords-mathematical culture; Huayao Dai people; costumes; geometric pattern

\section{INTRODUCTION}

Yunnan, located in the southwestern border of China is the province with the most ethnic minorities in China. In addition to the Han people, there are 25 minorities with a population of more than 5,000. The population of ethnic minority in the province accounts for nearly one-third of the total population. Yunnan's ethnic minorities are staggered, showing mixed and small settlements, and the Yi and Hui people are distributed throughout most of the county. In the long river of history, ethnic minorities in Yunnan gave birth to brilliant ethnic minority cultures and ethnic minority costumes were a special carrier of ethnic minority culture. The costumes of ethnic minorities is the crystallization of material culture and spiritual culture. Its formation, change and development, especially the formation of its regional and ethnic characteristics, depend not only on the constraints and influences objective factors such as geographical environment, natural conditions, production methods, and productivity, but also depend on the accumulation and portrayal of cultural and environmental factors such as ethnic history, cultural traditions, customs and etiquette, and religious beliefs. In each ethnic minority's costumes appearance, profound cultural connotation is contained[1]. Mathematics is an advanced culture as well as an important foundation for human civilization, of which the emergence and development accompany the process of human civilization and play an important role in it, occupying a decisive position. [2] Mathematics, as the product of human

*Fund Project: the Humanities and Social Sciences Research Project of the Ministry of Education "Research on the Production Protection and Traditional Manufacturing Process of the Huayao Dai people's costumes Culture in Xinping" (Project Number: 17YJC760071). civilization, has a close relationship with human civilization and human culture. Mathematics penetrates into every aspect of people's production and life. At the same time, it also reflects and mirrors human civilization at different stages. For the study of minority costumes, people have analyzed and interpreted from the perspectives of aesthetics, art, and folklore. However, it is rare to study ethnic costumes from the perspective of mathematics and culture. Mathematical culture is the sum of mathematics knowledge, methods of thought, its application in human activities, and folklore and beliefs related to mathematics. In the development of mathematics culture, scientific spirit, value orientation, aesthetic consciousness, and national cultural psychology play a promoting role. We can say that pure mathematics, history of mathematics, mathematical stories, geometric patterns, and figures with special significance are mathematical cultures, but the opposite is not true. For example, we can't say that mathematics culture is pure mathematics or mathematics culture is the history of mathematics, and so on. [3] This article attempts to study the "Huayao" Dai people costumes in Xinping, Yunnan from the perspective of mathematical culture, and excavates the mathematical culture contained in it. Through the study of minority mathematical culture and the inheritance, people can feel the mathematics around them, which has practical significance for enriching the connotation of mathematics, developing characteristic teaching resources in ethnic minority areas, and advancing the reform of mathematics curriculum in minority areas.

\section{RESEARCH METHODS}

In view of the research methods of anthropology, this research mainly adopts field investigations to study the mathematical elements of ethnic minority costumes culture. Members of the research group visited villages and towns where Huayao Dai people inhabit in Mosha, Yuzao, Yaojie, and Shuitang in Xinping She and Yi Autonomous County of Yunnan Province to conduct field investigation. They visited the inheritors of folk old people and ethnic culture, sorted out folk materials, and photographed ethnic costumes patterns to try to unearth the mathematical culture in ethnic minority costumes cultures. At the same time, they use literature 
review method to analyze and sort out the relevant literature of ethnic minority mathematical culture, in order to enrich the study of the mathematical factors in Huayao Dai people's costumes.

\section{The Mathematical Culture IN Huayao DaI PEOPLE COSTUMES}

\section{A. Brief Introduction to Huayao Dai People's Costumes}

"Huayao" Dai people are a conventional name for the Dai people mainly distributed in the Red River basin in Yunnan Province. There are many different branches of the Dai people that form and exist in the Red River Basin with different claims. For example, in Xinping Count in the upper reaches of the Red River, there are 3 branches including Daika, Daiya, and Daisa. There are 7 different branches in Yuanjiang County including Daika, Daiya, Daisa, Dailang, Daizhong, Daide and Daizhang. [4] The mainstream of the Red River flows through Xinping County and flows from the northwest to the southeast along the east side of main peak of the Ailaoshan Mountains, passing through Shuitang dam, Gasa dam and Mosha dam in turn. In the hot and humid river valleys, which are about 70 kilometers long and about 7 kilometers wide, the central area of the Huasha Dai culture is formed. Nearly 50,000 Huayao Dai people of three branches of Daisa, Daika and Daiya along the Yangtze River, are in one of the counties with the most Dai population in the counties of the Red River, accounting for over half of the total population of Huaiyao population in the country.

Xinping County is also a settlement of the Yi and Hani people. In the long-term national contact, it has been influenced by the aesthetic mentality of the "favoring black" of the Yi people. Black has become the keynote of HuaYao Dai people's costumes, and HuaYao Dai people's costumes is mostly made of black native cloth. Women's costumes usually has two pieces of clothing for upper part of body, and the outerwear is shorter than underwear. They wear five skirts underneath and tilt the hem to the left. Ribbons twine around the waist; and three to five aprons surround the waist, with one less than another, so that each piece exposes the upper lace of apron and wraps together to form a flower waist. Each waist line of Huayao Dai costumes has a colorful pattern on the waist, so it is called the "Huayao Dai" visually. Black leggings are made on the legs and the colored stripes corresponding to the waist are decorated. Huayao Dai people has the traditional practice of up-do, which refers to pulling hair into a hair plate behind the head, tying the hair tightly around the head with red, white, yellow, and green lace, and then wearing a round hat like blooming Termite Mushroom on the head. The women costumes of Huayao Dai people use a large number of silver ornaments. In addition to wearing silver earrings, round or square silver bracelets, and flower decoration silver rings, there are densely packed silver bubbles and sesame bells in their headscarves, inner jackets and outerwear. A triangular back decoration studded with silver pore and silver fringe hangs on the arm and a waistband with a silver-filled flower strap diagonally to the lower left, which will make a pleasant sound when people are walking. Huayao Dai people's costumes are colorful and have distinctive features that distinguish them from the clothing of other people or groups, forming unique visual symbols.

\section{B. Geometric Patterns in Huayao Dai People's Costumes}

From the perspective of geometric figure, the geometric patterns in Huayao Dai people's costumes mainly include points, lines, fold lines, triangles, squares, rectangles, diamonds, parallelograms, and circles, etc. These basic geometric figures form patterns through connection, symmetry, and combination, such as wan characteristic, clip pattern, well characteristic pattern, octagonal flowers, and saw tooth lines, and so on. "Fig. 1" is the commonly used lace in the Huayao Dai people's costumes. These patterns contain the positional relations between straight lines in geometry including perpendicular, intersecting, and parallel and so on. Using different colors to weave these geometric figures makes the entire pattern both regular and changeable, reflecting the symmetrical beauty of mathematics.

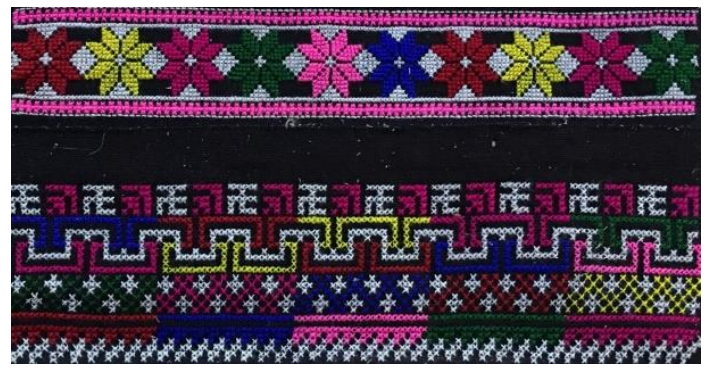

Fig. 1. Geometric patterns in Huayao Dai people's costumes.

From the perspective of geometrical patterns, there are a large number of geometric patterns in Huayao Dai people's costumes, such as straight lines, broken lines, and triangular lines, etc. These abstract geometric figures are patterns inherited from generation to generation, and are abstract expression for everyday life, so costumes pattern have a profound message as a symbol of art. Through field surveys, it can be found that most of the villages where Huayao Dai people live in are located at the foot of the Mount Ailao, on the valley of the Red River. With subtropical climate, it is called a "natural greenhouse". Since the natural climate is particularly suitable for the growth of rice, the Dai people living in the Red River Basin have been relying on rice cultivation as their main livelihood since ancient times. This "rice culture" also penetrates into all aspects of ethnic costumes. The geometric patterns in the local Daiya people's costumes, such as the straight line pattern, diamond pattern, fold line pattern, triangular pattern, butterfly pattern, and fish pattern, etc., reflect the scenes of the daily work of ethnic minorities. For example, the triangular pattern represents continuous mountains, the diamond pattern represents paddy field, the fold line pattern represents a river, the black symbolizes the soil, the green color compares to rice, the leaves of the trees or the forest, the red part symbolizes the fruit of the tree, and the lace inlaid with various colors symbolizes rainbow. Triangular line pattern and fold line pattern are prominent in Huayao Dai people's costumes and are frequently used. "Fig. 2" is a triangular pattern decorated 
with the collar of the women's coat of Taiya branch, which is inlaid with tiny silver bubbles. Such triangles are often decorated on the collar or chest, and triangles are staggered with silver pore, forming a continuous fold line. As shown in "Fig. 3", it is a fold line pattern that is decorated on the apron. There are many variations in the style of the Huayao Dai people's costumes, all of which are represented by a variety of continuous fold lines. These are common in the flower waist dresses. These patterns are closely associated with the geographical environment of the mountains and rivers where Huayao Dai lives for generations. It is an abstract expression of the landscape, which symbolizes the vertical and horizontal rivers and mountains that people experienced during the migration process. The broken lines also symbolize the hardships and helplessness they have experienced.

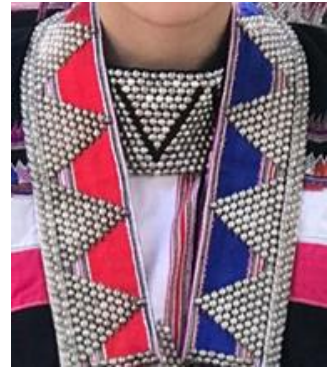

Fig. 2. Triangle pattern.

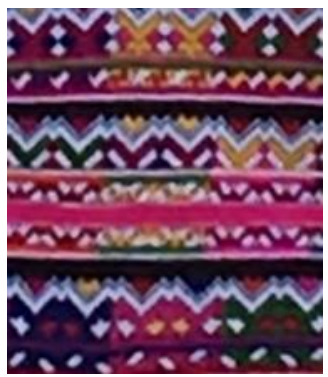

Fig. 3. Fold line pattern.

\section{Geometric Transformations in Geometric Patterns}

The patterns in costumes can be divided into individual patterns and continuous patterns. The so-called individual patterns are patterns that have no continuity with the surroundings and have relative independence and integrity. The individual patterns in Huayao Dai people's costumes are usually symmetrical. Some patterns are both axisymmetric and center symmetrical, reflecting the symmetrical beauty of mathematics. The octagonal pattern is a very unique pattern in the Huayao Dai people's costumes. The octagonal pattern symbolizes the infinite power of the sun, so Huayao Dai people embroiders the octagonal pattern on their costumes in the hope of being blessed by the gods to create more wealth for them. The octagonal pattern consists of eight congruent parallelograms with four symmetry axes, as shown in "Fig. 4". There is a lot of deformation in the octagonal pattern in Huayao Dai people's costumes, as shown in "Fig. 5". Through the use of different colors, the geometric shapes such as triangles and squares are combined into the shape of the octagonal pattern, which not only maintains the uniform style of the pattern, but also has changes. This greatly enriched the types of decorative patterns, reflecting the beauty of the combination and of symmetry in the basic geometric figure of mathematics.

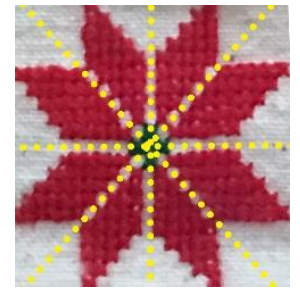

Fig. 4. Octagonal pattern.

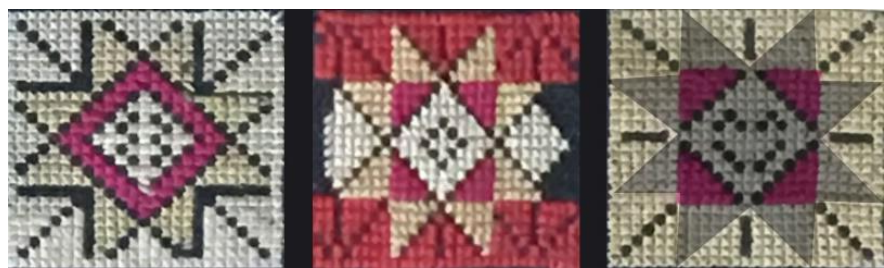

Fig. 5. Several variations of octagonal pattern.

The individual pattern can be said to be the basic unit consisting the pattern, and the continuous pattern can be constructed by two-side pattern and four-side pattern of the individual patterns. A continuous pattern is a combination of individual patterns, which refers to the pattern that is repeatedly arranged according to a certain rule by unit pattern that is firstly composed of one or more decorative patterns. Two-side pattern is a continuous pattern formed by a unit pattern being reversed in the left-right or up-down direction. The two-side patterns usually form a banded decorative pattern and are often used for decoration on collars, belts, skirts, and leggings and so on. "Fig. 6" is a pattern formed by repeatedly arranging octagonal lines in the left and right direction. From a mathematical point of view, two-sided pattern actually transform a unit pattern horizontally or vertically and constructs a continuous geometric figures through translation. Such examples are numerous in the Huayao Dai people's costumes. The clip pattern on the upper half in "Fig. 6", and the diamond pattern in the middle part all reflect the translation of this figure.

The four-side pattern and the two-said pattern are different. It construct the planar pattern by repeatedly arranging the unit pattern in the upward, downward, leftward, and rightward orientations regularly and infinitely extending. From the perspective of mathematics, the two-side pattern constructs a one-dimensional pattern while the four consecutive units construct a two-dimensional pattern. As shown in "Fig. 7", the octagonal lines are translated in horizontal and vertical directions to construct a whole picture. 


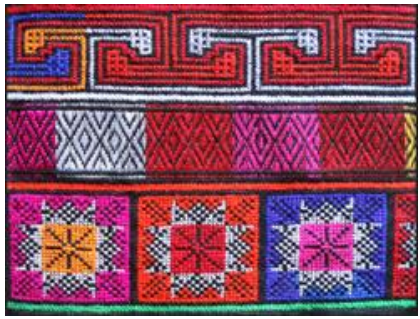

Fig. 6. Two-side pattern.

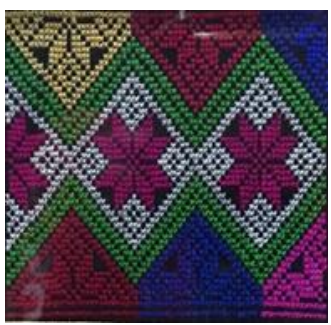

Fig. 7. Four-side pattern.

By analyzing the geometric pattern of the lumbosacral ridge from the viewpoint of transformation, whether it is two-side pattern or four-side pattern, the morphological representation of the continuous pattern is mainly the equal equivalence transformation of elementary geometry, including translation transformation, rotation transformation, and axial reflection transformation, in which the translation transformation includes common point translations, collinear translations, and equidistant translations. Complex geometrical patterns consist of basic geometric shapes such as line segments, rectangles, right triangles, squares, and parallelograms, etc. These patterns are transformed, symmetric, rotated, and combined to form a rich variety of patterns. By using different colors, beautiful patterns are created. This not only is the beauty of the pattern, but also embodies the beauty of mathematics.

\section{The Golden Section in the Dai Costumes}

The "Golden Section" is an important principle in aesthetics and architecture. There was a record about golden section on the prehistoric stone columns in the 20th to 16th century BC.

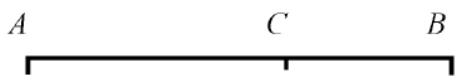

Fig. 8. The golden section of line segment.

By Renaissance, artists and architects applied the golden section in sculptures, paintings, and architecture. From the perspective of geometry, the golden section refers to a ratio. As shown in Fig. 8, there is a point $\mathrm{C}$ on segment $\mathrm{AB}$ and point $\mathrm{C}$ divides the segment $\mathrm{AB}$ into two segments. If $\frac{A C}{A B}=\frac{C B}{A C} \approx 0.618$, point $C$ is called the golden section point of the segment $\mathrm{AB}$. With the golden section, the golden rectangle can be defined. In ancient Greece, a rectangle with a width and length ratio equal to 0.618 is called a golden rectangle. The golden section is generally found in the natural world. There is also golden section in the human body. If people's height is considered to be a line segment, when the navel is exactly the golden section point of this segment, the human body appears to be the most harmonious and beautiful. At this time, the length from the sole of the foot to the navel is about 0.618 times the height of the entire body. However, most people cannot reach this perfect ratio. The length from the bottom of the foot to the navel is always shorter, making the ratio about 0.6 , which can't reach 0.618 . Therefore, in modern life, the length of the legs is often increased by wearing high-heeled shoes, thereby increasing the proportion of the foot from the navel to the navel in the total length and make the ratio as close as possible to 0.618 . Some scholars have conducted research from a statistical point of view that wearing high heels with a height of about $6 \mathrm{~cm}$ can effectively correct the relationship of ratio between the leg length and height of the human body, and make it in line with the golden ratio. This is the aesthetic effect of highheeled shoes and is also the reason for its popularity. [5] Huayao Dai women's tops are shorter, usually above the navel, with a colorful belt around their waists and a long skirt. As shown in the figure, if the height of human body is regarded as the line segment $A B$ and the position of the navel is $\mathrm{C}$, the proportion of the human body cannot reach the golden section, which is $\frac{A C}{A B}<0.618$, but the colorful belt will visually increase the position of the waistline, thus increasing the proportion of the bottom of the feet to the navel in the entire length and making the legs look more slender, so the effect is the same as that of high-heeled shoes.

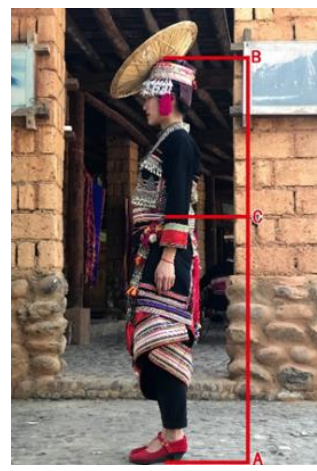

Fig. 9. Side face of Huayao Dai people's costumes

\section{CONCLUSION}

There is a large amount of mathematics culture in Huayao Dai people's costumes. Besides, the mathematical thoughts and methods permeate in each aspect of production and life in ethnic minorities such as architecture, languages, and writings, constituting the mathematical culture of ethnic minorities. The significance of national mathematics culture lies not only in that it is an important part of national culture, but also in its practical role and value in school education. For example, the national mathematics culture is conducive to the individualized teaching by combining the minority children to reform the content of the mathematics curriculum, such as the compilation of local teaching materials. [6] Each ethnic group has its own unique cultural system. The content of school education in ethnic areas must be closely integrated 
with it in order to stimulate the interest of learners and to form a soil for the intangible cultural heritage of the nation. [7] Digging out the educational value of mathematics culture from carriers such as costumes and buildings of ethnic minorities has yet to be further studied by mathematics education researchers.

\section{REFERENCES}

[1] $\mathrm{Hu}$ Jingping. Costumes culture of ethnic minorities in China [J]. Study of Ethnics in Guangxi, 2001(1): 62-68. 胡敬萍.中国少数民族 的服饰文化 $[\mathrm{J}]$. 广西民族研究, 2001（1）：62-68.

[2] Li Daqian. Mathematical Culture and Mathematics Education[J]. China University Teaching, 2008(10). 李大潜. 数学文化与数学教养 [J].中国大学教学, 2008(10)

[3] Dai Qin. Interpretation of Mathematical Culture[J]. Bulletin des Sciences Mathematics, 2013(4):1-4. 代钦. 释数学文化 [J]. 数学通 报, 2013(4): 1-4

[4] Gou Shuangxiao. The Origin of Huayao Dai people's costumes Culture [J]. Journal of Chongqing University of Arts and Sciences (Social Science Edition), 2013(2): 56-60. 苟双晓.花腰傣服饰文化探 源 [J]. 重庆文理学院学报（社会科学版），2013（2）：56-60

[5] Zhao Zhijun. The aesthetic effect of high heels from a statistical point of view [J] Statistics \& Decision, 1994(2). 赵志君. 从统计观点看高 跟鞋的美学效果 $[\mathrm{J}]$ 统计与决策, 1994（2）

[6] Lv Chuanhan, Zhang Honglin. National Mathematical Culture and Mathematics Education [J]. Journal of Mathematics Education, 1992, (1). 吕传汉, 张洪林. 民族数学文化与数学教育 [J].数学教育学 报, 1992, (1)

[7] He Nengkun, Zhang Xuemin. The Construction of a New Mechanism for the Inheritance of Non-material Cultures of Ethnic Minorities[J]. Ethnic Education Study, 2008, (6). 贺能坤, 张学敏.构建少数民族 非物质文化传承的新机制 [J].民族教育研究，2008，(6). 